\title{
Was bewirkt die Mittelmeerdiät beim Typ-2-Diabetes?
}

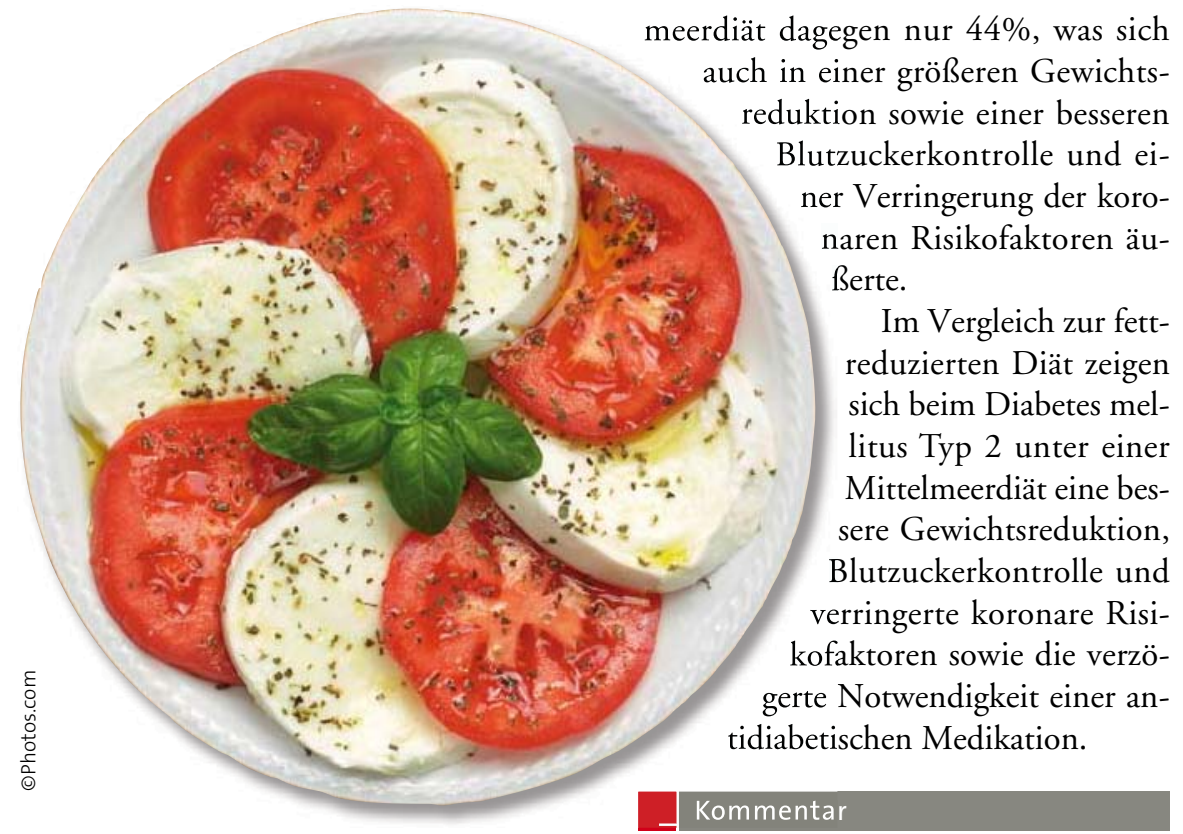

Besser kohlenhydrat- als fettreduziert.

Übergewichtigen Typ-2-Diabetikern werden sowohl kohlenhydratreduzierte (Mittelmeerdiät) als auch fettreduzierte Diäten zur Gewichtsreduktion empfohlen. Stellt sich die Frage, wie sich die jeweilige Diätform auf die Notwendigkeit einer medikamentösen Behandlung des Diabetes auswirkt.

_ 215 Patienten an einem italienischen Lehrkrankenhaus, bei denen erstmalig ein Diabetes mellitus Typ 2 mit einem $\mathrm{HbA}_{1 \mathrm{c}}$-Wert $<11 \%$ diagnostiziert worden war, wurden entweder einer kohlenhydrat- oder einer fettreduzierten Diät zugeteilt. Neben der Gewichtsveränderung, dem Blutzucker und koronaren Risikofaktoren wurde auch registriert, wann die Probanden eine antihyperglykämische Medikation benötigten.

Nach einem Beobachtungszeitraum von vier Jahren erhielten in der Gruppe der Teilnehmer an der fettreduzierten Diät 70\% der Patienten eine antidiabetische Medikation, in der Gruppe mit der kohlenhydratreduzierten Mittel-
Esposito et al. zeigen in ihrer randomisierten Studie deutlich, dass die Modifizierung der Ernährungsgewohnheiten einen entscheidenden Aspekt für den Krankheitsverlauf beim Typ-2-Diabetes darstellt. Diese Umstellung ist sicher im Alltag schwerer umzusetzen und bedarf initial einer intensiveren Schulung als der Einsatz eines oralen Antidiabetikums oder einer raschen Kombinationstherapie. Aufseiten des Patienten und des Behandlers ist hier ein entsprechendes Engagement gefragt. So richtig überraschend ist dieses Ergebnis nicht und auch nicht ganz neu. Allerdings handelt es sich erneut um einen Beitrag, der aufzeigt, wie wenig hier oftmals getan wird und was eigentlich alles erreicht werden könnte. Diese Studie liefert damit in der Beratung eine weitere wertvolle Diskussionsgrundlage im Hinblick auf die erste Zeit nach der Diagnosestellung eines Typ-2-Diabetes.

Dr. med. Alexander H. JAKob, BAD HOMBURG V. D. H. .

- K. Esposito et al.

Effects of a mediterranean style diet on the need for antihyperglycemic drug therapy in patients with newly diagnosed type 2 diabetes. Ann Intern Med 151 (2009) 306-314 